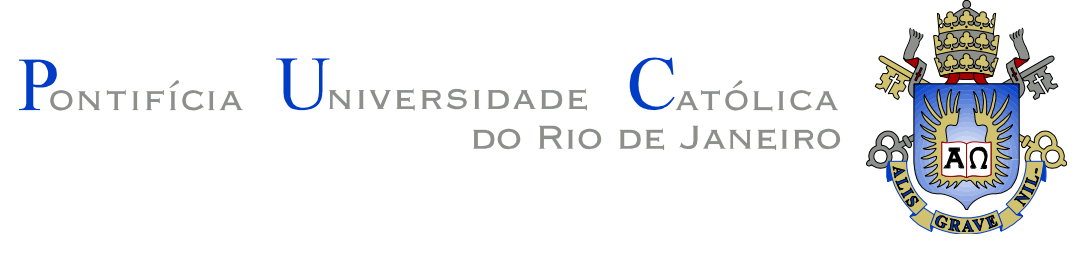

Antonio Aparecido Alves

\begin{abstract}
Escolas de Formação Fé e Política. Um estudo teológico a partir do Ensino Social da Igreja e da Teologia latino-americana.
\end{abstract}

Tese de Doutorado

Tese apresentada ao Programa de PósGraduação em Teologia da PUC-Rio como parte dos requisitos parciais para a obtenção do título de Doutor em Teologia.

Orientador: Paulo Fernando Carneiro de Andrade.

Rio de Janeiro, fevereiro de 2010 


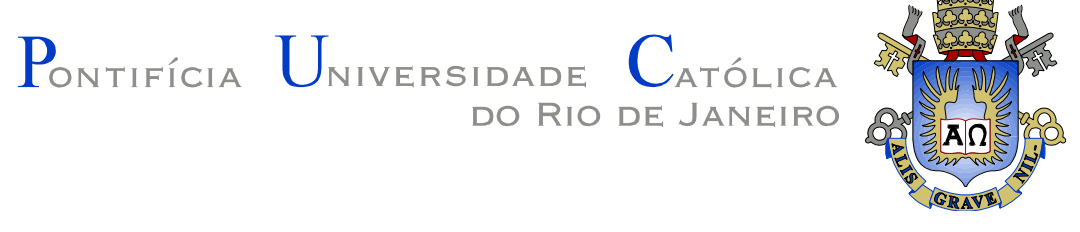

Antonio Aparecido Alves

\title{
Escolas de Formação Fé e Política. Um estudo teológico a partir do Ensino Social da Igreja e da Teologia latino- americana.
}

Tese apresentada como requisito parcial para obtenção do grau de Doutor pelo Programa de Pós-Graduação em Teologia do Departamento de Teologia do Centro de Teologia e Ciências Humanas da PUC-Rio. Aprovada pela Comissão Examinadora abaixo assinada.

\author{
Prof. Paulo Fernando Carneiro de Andrade \\ Orientador \\ Departamento de Teologia - PUC-Rio \\ Prof $^{\mathrm{a}}$ Maria Clara Lucchetti Bingemer \\ Departamento de Teologia - PUC-Rio \\ Prof. Luis Corrêa Lima \\ Departamento de Teologia - PUC-Rio
}

Prof. Pedro de Assis Ribeiro de Oliveira

PUC-MG

Prof. Carlos Alberto Steil Universidade Federal do Rio Grande do Sul

Prof. Paulo Fernando Carneiro de Andrade Coordenador Setorial de Pós-Graduação e Pesquisa do Centro de Teologia e Ciências Humanas - PUC-Rio.

Rio de Janeiro, 11 de março de 2010 
Todos os direitos reservados. É proibida a reprodução total ou parcial do trabalho sem autorização da universidade, do autor e do orientador.

\section{Antonio Aparecido Alves}

Bacharel em Teologia pela Pontifícia Universidade Católica do Rio de Janeiro. Mestre em Ciências Sociais, com especialização em Doutrina Social da Igreja, pela Pontifícia Universidade Gregoriana de Roma. Diretor da Escola de Política e Cidadania da Diocese de São José dos Campos. Professor no Instituto de Teologia e Filosofia Santa Teresinha, da Diocese de São José dos Campos, e na Faculdade Dehoniana, em Taubaté (SP). Presbítero na Diocese de São José dos Campos (SP).

\section{Ficha Catalográfica}

Alves, Antonio Aparecido

Escolas de formação fé e política : um estudo teológico a partir do ensino social da igreja e da teologia latino-americana / Antonio Aparecido Alves ; orientador: Paulo Fernando Carneiro de Andrade - 2010.

$$
250 \text { f. ; } 30 \mathrm{~cm}
$$

Tese (Doutorado em Teologia)-Pontifícia Universidade Católica do Rio de Janeiro, Rio de Janeiro, 2010.

Inclui bibliografia

1. Teologia - Teses. 2. Fé e política. 3. Reino de Deus. 4. Ensino social da Igreja. 5. Transformação social. 6. Caridade. 7. Justiça. I. Andrade, Paulo Fernando Carneiro de. II. Pontifícia Universidade Católica do Rio de Janeiro. Departamento de Teologia. III. Título. 
A Dom Nelson Westrupp, por ter acreditado em minhas potencialidades.

Aos que se empenham nas Escolas de Formação Fé e Política, buscando outra Política possível.

Aos companheiros e companheiras da AESI e da Escola de Política e Cidadania da Diocese de São José dos Campos/SP, com os quais compartilho a utopia de um mundo novo. 


\section{Agradecimentos}

Ao Departamento de Teologia da PUC-Rio, pela acolhida.

À CAPES e à PUC-Rio, pelo auxílio financeiro concedido para essa pesquisa.

Ao professor Paulo Fernando Carneiro de Andrade, pela orientação segura.

À Diocese de São José dos Campos/SP, pela oportunidade e apoio oferecidos.

Às diversas Escolas de Formação Fé e Política, pela ajuda imprescindível.

À Faculdade Dehoniana, especialmente a Anna e Yeda, pelo uso da biblioteca.

Aos familiares, presbitério e amigos, pela paciência e incentivo. 


\section{Resumo}

Alves, Antonio Aparecido; Andrade, Paulo Fernando Carneiro. Escolas de Formação Fé e Política. Um estudo teológico a partir do Ensino Social da Igreja e da Teologia latino-americana. Rio de Janeiro, 2010, 250p. Tese de Doutorado - Departamento de Teologia da Pontifícia Universidade Católica do Rio de Janeiro.

As Escolas de Formação Fé e Política são uma feição contemporânea da formação política dos cristãos na Igreja do Brasil. Conhecer a origem desse novo modelo de formação, mapear essas escolas e socializar suas experiências têm grande relevância pastoral, sendo que neste trabalho são apresentadas treze escolas. A tese que se defende nesta pesquisa é a de que existe uma teologia subjacente a estas escolas e, por isto, seu objetivo principal é o de fazer um estudo teológico dos objetivos, programas e conteúdos de formação das escolas, tendo como parâmetro o Ensino Social da Igreja e a Teologia latino-americana. No que se refere ao Ensino Social da Igreja, será seguida a indicação da Evangelii Nuntiandi, tendo como base a Constituição Pastoral Gaudium et Spes e demais documentos da Doutrina Social da Igreja. No que tange a Teologia latinoamericana, serão consideradas sua metodologia e sua reflexão teológica, bem como os modelos teológicos de relação Fé e Política engendrados por teólogos deste continente. A conclusão a que se chegou é que existem ênfases teológicas diversas, presentes nas Escolas de Formação Fé e Política.

\section{Palavras-chave}

Fé e Política; Reino de Deus; Ensino Social da Igreja; Transformação social; Caridade; Justiça. 


\section{Abstract}

Alves, Antonio Aparecido; Andrade, Paulo Fernando Carneiro (advisor). Faith and Politics Formation Schools. A theological study based on the Social Teaching of the Church and in Latin American theology. Rio de Janeiro, 2010, 248p. Doctoral Thesis - Departamento de Teologia da Pontifícia Universidade Católica do Rio de Janeiro.

The Faith and Politics Formation Schools are a contemporary expression of the Christian political formation at the Brazilian Catholic Church. To know the source of this new formation model, to map these schools and socialize their experiences is a very important pastoral task, so this work presents thirteen schools. The proposed thesis in this research is that there is a theology that underlies these schools and, therefore, in this work, the main objective is to develop a theological study of its objectives, programs and content related to the formation, based on the Social Teaching of the Church and in Latin American theology, as a perspective. Regarding the Social Teaching of the Church, it will be followed an indication of Evangelii Nuntiandi, based on the Pastoral Constitution Gaudium et Spes, and other documents of the Social Doctrine of the Church. As far as Latin American Theology, it will be considered its methodology and its theological reflection, as well as the theological models of the relationship between Faith and Politics', engendered by theologians of this continent. The conclusion reached is that there are different theological emphasis present in Faith and Politics Formation Schools.

\section{Keywords}

Faith and Politics; Kingdom of God; Church's Social Teaching; charity; justice; sociopolitical commitment. 


\section{Sumário}

1 Introdução 13

1.1. Relevância teológico-pastoral do tema estudado 14

1.2. Apresentação do trabalho e sua contribuição para

$\begin{array}{ll}\text { compreensão das questões envolvidas } & 19\end{array}$

2 Experiências histórico-pastorais de formação Fé e Política 25

2.1. Inserir a Igreja de maneira afirmativa na sociedade 26

2.2. Transformar as estruturas sociais $\quad 34$

2.3. Unir de modo novo Fé e Vida na comunidade eclesial 42

$\begin{array}{ll}\text { 2.4. Preparar os cristãos para as eleições. } & 48\end{array}$

2.5. Formar para um desenvolvimento social 51

2.6. Considerações finais $\quad 55$

3 Gênese das Escolas de Formação Fé e Política 58

3.1. A mudança de paradigma nos anos 1990

3.2. A Evangelização como Objetivo Geral da Igreja

$\begin{array}{ll}\text { do Brasil } & 62\end{array}$

3.3. Mapeamento e classificação das Escolas de Formação

$\begin{array}{ll}\text { Fé e Política } & 68\end{array}$

3.4. Experiências concretas de Escolas de Formação Fé e Política 70

3.5. Considerações finais 99

4 Aspectos de ordem antropológica e evangélica, pertinentes a uma articulação e formação Fé e Política 101

4.1. O ser humano no mistério do mundo e da história 102

4.1.1. A relação pessoa-sociedade e suas implicâncias 
para a relação Fé e Política

4.1.2. Dimensão sócio-transformadora da atividade

humana

107

4.2. Entre a esperança e a utopia 114

4.3. Os Direitos humanos 120

4.4. A caridade: exigência evangélica, compromisso de fé e desafio pastoral

4.5. A caridade no magistério de Bento XVI

4.6. O amor como elemento organizador da sociedade

132

4.7. O empenho pela justiça, exigência mínima

da caridade

135

4.8. O bem comum como realização da justiça e da agape 139

4.9. Considerações finais

141

5 Elementos bíblico-teológicos relevantes para uma

articulação e formação Fé e Política

146

5.1. A criação, primeiro ato libertador do Deus

todo-poderoso e solidário

5.2. A opção preferencial pelos pobres 154

5.3. Do Deus presente ao Verbo encarnado.

157

5.4. O Reino de Deus como paradigma da pregação

de Jesus e da ação cristã 161

5.5. A redenção da ordem política

5.6. Considerações finais

6 A teologia subjacente às Escolas de Formação

Fé e Política

6.1. Uma teologia do engajamento sociopolítico. 
6.2. A relação Fé e Política, a partir da Teologia latino-americana $\quad 180$

6.3. Uma teologia moral, de corte social 194

6.4. O protagonismo dos leigos 198

6.5. Considerações finais 201

7 Conclusão 206

8 Referências bibliograficas 211

9 Anexo. Programas das Escolas da Formação Fé e Política 242 


\title{
Siglas
}

\author{
$\mathrm{ABC}=$ Santo Amaro, São Bernardo, São Caetano \\ $\mathrm{ACB}=$ Ação Católica Brasileira \\ ACO = Ação Católica Operária \\ AESI $=$ Associação para o Ensino Social da Igreja \\ AUC = Ação Universitária Católica \\ $\mathrm{CCB}=$ Centro Cultural de Brasília \\ $\mathrm{CDI}=$ Centro de Documentação e Informação da CNBB \\ Cefep $=$ Centro Nacional de Fé e Política \\ CIAS = Centro de Investigação e Ação social \\ Celam $=$ Conselho Episcopal Latino-americano \\ Cepat $=$ Centro de Pesquisas e Apoio ao Trabalhador \\ Cepis = Centro de Educação Popular do Instituto Sedes Sapientiae . \\ $\mathrm{CF}=$ Campanha da Fraternidade \\ Consep $=$ Conselho Permanente \\ CUT $=$ Central Única dos Trabalhadores \\ DSI $=$ Doutrina Social da Igreja \\ EDEP = Escola Diocesana de Educação Política de Limeira \\ EPC = Escola de Política e Cidadania de São José dos Campos \\ GCAP = Grupo Cristão de Atuação Política \\ Ibrades $=$ Instituto Brasileiro de Desenvolvimento \\ ICES = Instituto Católico de Estudos Superiores \\ INP = Instituto Nacional de Pastoral \\ Itepa $=$ Instituto Teológico de Passo Fundo \\ JOC = Juventude Operária Católica \\ JUC $=$ Juventude Universitária Católica \\ LEC $=$ Liga Eleitoral Católica \\ MEB = Movimento de Educação de Base \\ $\mathrm{PL}=$ Patrologiae Latinae \\ RCC $=$ Renovação Carismática Católica \\ REB $=$ Revista Eclesiástica Brasileira \\ SAR = Serviço de Animação Rural \\ Sares $=$ Serviço de Ação, Reflexão e Educação Social \\ $\mathrm{UNE}=$ União Nacional dos Estudantes \\ Unicentro = Universidade Estadual do Centro-Oeste do Paraná.
}


"Uma pessoa se faz revolucionária não movida pelo estudo, mas por causa de uma indignação ética. $\mathrm{O}$ estudo vem depois, para preencher e dar precisão a este protesto".

(Merleau-Ponty). 